\title{
Definition of efficient scarcity-based water pricing policies through stochastic programming
}

\author{
H. Macian-Sorribes ${ }^{1}$, M. Pulido-Velazquez ${ }^{1}$, and A. Tilmant ${ }^{2}$ \\ ${ }^{1}$ Research Institute of Water and Environmental Engineering (IIAMA), Universitat Politècnica de València, Valencia, Spain \\ ${ }^{2}$ Department of Civil and Water Engineering, Université Laval, Québec City, Québec, Canada
}

Correspondence to: H. Macian-Sorribes (hecmasor@upv.es)

Received: 9 December 2014 - Published in Hydrol. Earth Syst. Sci. Discuss.: 19 January 2015

Revised: 2 September 2015 - Accepted: 7 September 2015 - Published: 23 September 2015

\begin{abstract}
Finding ways to improve the efficiency in water usage is one of the most important challenges in integrated water resources management. One of the most promising solutions is the use of scarcity-based pricing policies. This contribution presents a procedure to design efficient pricing policies based on the opportunity cost of water at the basin scale. Time series of the marginal value of water are obtained using a stochastic hydro-economic model. Those series are then post-processed to define step pricing policies, which depend on the state of the system at each time step. The case study of the Mijares River basin system (Spain) is used to illustrate the method. The results show that the application of scarcitybased pricing policies increases the economic efficiency of water use in the basin, allocating water to the highest-value uses and generating an incentive for water conservation during the scarcity periods. The resulting benefits are close to those obtained with the economically optimal decisions.
\end{abstract}

\section{Introduction}

One of the main challenges in integrated water resources management (IWRM) is improving the efficiency in water usage while balancing it with equity. Given that in the majority of the developed world the building of new water supply systems has well passed its zenith, water management strategies are now devoted to achieve better operating policies. Several criteria can be considered when designing a policy for water allocation: flexibility in the allocation, security of tenure for the users, real cost recovery, predictability of its performance, fairness and acceptability (Dinar et al., 2007). Each system has a unique configuration and, in consequence, a unique combination of factors that lead to an adequate management policy.

There are four major water allocation mechanisms: public water allocation, water markets, user-based allocation and marginal cost pricing. Public water allocation provides an adequate treatment of water as a public good, allows for the development of large-scale infrastructures often beyond the private investment capacity, and focuses on equity issues and non-economic objectives. However, it usually fails in achieving optimal economic performance, leads to water prices which are below the water value, and provides no incentive to water saving and efficient use (Meinzen-Dick and Mendoza, 1996). Water markets encourage both sellers and buyers to use it efficiently, provide flexible allocation mechanisms and allow considering the real value of the employed resource. On the contrary, unique characteristics of water can turn markets into a bad allocation mechanism if externalities are not adequately considered (Garrick et al., 2009). User-based allocation, in which water users regulate water resources by themselves, is especially suited for local needs in water management and is likely to be accepted by the users. However, it may be inadequate in inter-sectorial allocation, requiring also a very transparent structure (Dinar et al., 2007).

Finally, marginal cost pricing provides a theoretically adequate way to consider water values in allocation, encourages users to save it and puts water in its most valuable uses, leading to efficient allocations. It also can play a major role in the long-term planning and conservation of water supplies, delaying the need of capacity expansions and offering higher economic returns while holding rationing requirements (Gysi and Loucks, 1971). However, marginal cost pricing would require estimating the non-accounting opportunity costs in- 
volved in water allocation (Griffin, 2001). Calculating the marginal value of water is challenging as it varies in space and time according to supply-demand imbalances, requires adequate monitoring, and has some difficulties to deal with equity when water prices are beyond what lower-value users can afford (Dinar et al., 2007). Moreover, administrative constraints on price charges can limit their benefits (Dandy et al., 1984). In Europe, the EU Water Framework Directive (European Commission, 2000) calls for the implementation of new pricing policies that assure the contribution of water users to the recovery of the cost of water services (financial instrument) while providing adequate incentives for an efficient use of water (economic instrument). Not only financial costs should be recovered but also environmental and resource (opportunity) costs. This issue has been addressed through the use of hydro-economic models as tools able to couple physical and economic water resource aspects (Heinz et al., 2007; Pulido-Velazquez et al., 2008, 2013; Riegels et al., 2013; Ward and Pulido-Velazquez, 2008).

A pricing policy is efficient, according to economic theory, if the prices charged correspond to the marginal cost of water. Therefore, it must take into account supply costs, opportunity costs and externalities (Rogers et al., 2002). Measuring the opportunity costs of scarce water is difficult: since water markets are usually absent or ineffective, scarcity values are not reflected in the water prices. Given that opportunity cost depends on the alternative uses, an integrated basinwide approach is needed to simultaneously account for all major competing water uses in the basin (Rogers et al., 2002; Pulido-Velazquez et al., 2013). The assessment of these opportunity costs requires a systems approach and a proper method to estimate the value of water across the different users (Young, 2005; Pulido-Velazquez et al., 2008). If pricing policies reflect the entire basin-wide marginal opportunity costs, then they will act as an economic instrument for efficient water resources management, modifying the demandsupply interaction by acting on the demand side and supporting water allocation to the most valuable users.

The marginal resource opportunity cost (MROC), or marginal value of water, can be defined as the benefits that would have been obtained at one location and one time if the available resource at that location and time had been increased by one unit (Pulido-Velazquez et al., 2008, 2013; Tilmant et al., 2008, 2014). MROC can be derived from hydro-economic models. Pulido-Velazquez et al. (2013) developed a method to obtain scarcity-based pricing policies using MROC values, in which the time series of MROC obtained after running a hydro-economic model are postprocessed to derive step pricing policies whose performance can be simulated using a decision support system (DSS) shell. However, in those studies pricing policies were based on either priority-based simulation (which are not representing an optimal policy) or deterministic hydro-economic optimization, with the inherent limitation of the perfect foresight (the optimization algorithm knows future flows in advance

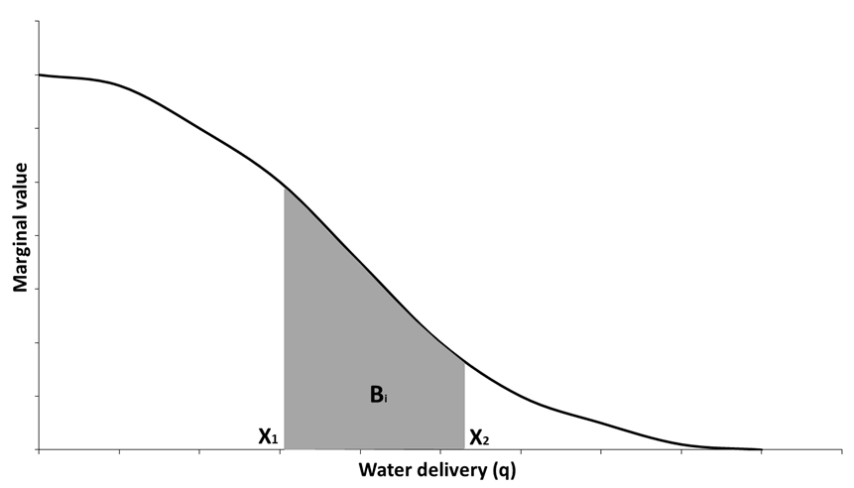

Figure 1. Benefits from an increase of water delivery from $x_{1}$ to $x_{2}$.

and, in consequence, it has an unrealistic advantage that diminishes the applicability of the results) (Labadie, 2004).

The main purpose of this paper is to propose a method for the design of scarcity-based water pricing policies based on the MROC derived from a stochastic hydro-economic model. With stochastic programming procedures, uncertainty is taken into account in the optimization process. Therefore, it removes the effect that the "perfect foresight" phenomenon causes in the marginal values, which are flattened across time and thus lose an important part of their short-term variability. The marginal values obtained using stochastic programming are representative of an optimal policy while reflecting the future uncertainties in the system's inflows. After describing the method to obtain the MROC values, we propose a method for the definition of a stochastic-programming-based water pricing policy. Finally, a case study is developed to prove and illustrate the methodology using a hydro-economic simulation model of the Mijares River basin system (Spain). Pricing policies are applied in this paper exclusively as economic instruments whose purpose is achieving an efficient use of water. Financial issues are not addressed.

\section{Method and materials}

\subsection{Assessment of the marginal resource opportunity cost (MROC)}

For a specific water demand, the benefit obtained by the user, $B_{i}$, given a change in water delivery level from $x_{1}$ to $x_{2}$, can be calculated by integrating the demand curve $\left(D_{i}\right)$ (Fig. 1):

$B_{i}=\int_{x_{1}}^{x_{2}} D_{i}(q) \mathrm{d} q$.

Similarly, for a given location $L$ and time $t$, the benefit $B_{t}$ achieved by a change in its state $s_{L, t}$ (water availability) from $x_{1}$ to $x_{2}$ can be calculated integrating the marginal water 
value (or MROC) function:

$$
B_{t}=\int_{x_{1}}^{x_{2}} \operatorname{MROC}_{L, t}\left(s_{L, t}\right) \mathrm{d} s .
$$

The MROC can be defined as the derivative of the benefit function with respect to the system state. Therefore, if the MROC integration obtains the system-wide benefits, the MROC can be calculated as

$\operatorname{MROC}_{L, t}=\frac{\mathrm{d} B_{t}\left(s_{L, t}\right)}{\mathrm{d} s}$.

The MROC value for a specific location and time can be estimated (1) under a simulation approach, as the benefits obtained by an increase of one unit in the available resource at that location and time (Pulido-Velazquez et al., 2008, 2013); and (2) under an optimization approach, as the shadow value, dual variable or Lagrange multiplier associated with the mass-balance equation at the desired place and the specified time (Pulido-Velazquez et al., 2008, 2013; Tilmant et al., 2008).

\subsection{MROC assessment through stochastic programming}

Stochastic programming (SP) procedures are powerful and useful methodologies to derive optimal management of water systems with uncertain inputs (Tejada-Guibert et al., 1993). Various SP algorithms are available. Among them, stochastic dynamic programming (SDP) has been widely used in water resources management because (1) it is able to handle non-linearities in the objective function in an efficient way, (2) the inflow uncertainty representation is clear and simple, and (3) it treats the decision-making process sequentially, as done in real-life operation (Labadie, 2004). The SDP algorithm solves the Bellman's recursive equation as follows:

$$
\begin{aligned}
& F_{t}\left(\boldsymbol{S}_{t}, \boldsymbol{Q}_{t}\right) \\
& =\max _{D_{t}}\left[B_{t}\left(\boldsymbol{S}_{t}, \boldsymbol{Q}_{t}, D_{t}\right)+E_{\boldsymbol{Q}_{t+1} \mid \boldsymbol{Q}_{t}}\left\{F_{t+1}\left(\boldsymbol{S}_{t+1}, \boldsymbol{Q}_{t+1}\right)\right\}\right]
\end{aligned}
$$

where $F_{t}$ is the total benefit function, $S_{t}$ the current (time $t$ ) system state vector, $\boldsymbol{Q}_{t}$ the current inflow vector, $D_{t}$ the decision made at time step $t, B_{t}$ the immediate benefit function, $E_{\boldsymbol{Q}_{t+1} \mid \boldsymbol{Q}_{t}}$ the expectation operator between the current and future inflows, and $F_{t+1}$ the future benefit function or benefit-to-go function.

In the SDP method, the state variables $\boldsymbol{S}_{t}$ and $\boldsymbol{Q}_{t}$ are discretized over all the state space forming a grid, allowing only transitions between grid points. The expectation operator is then defined by using a Markov chain that relates the current hydrological state $\boldsymbol{Q}_{t}$ to all the possible future states $\boldsymbol{Q}_{t+1}$ through a set of transition probabilities.

With the application of Eq. (4), the optimal policies $D_{t}\left(\boldsymbol{S}_{t}, \boldsymbol{Q}_{t}\right)$ and benefit-to-go function $F_{t}\left(\boldsymbol{S}_{t}, \boldsymbol{Q}_{t}\right)$ are calculated at the grid points. Then, interpolation methodologies can be applied to obtain the optimal policies $D_{t}^{*}\left(\boldsymbol{S}_{t}, \boldsymbol{Q}_{t}\right)$ and the optimal benefits $F_{t}^{*}\left(\boldsymbol{S}_{t}, \boldsymbol{Q}_{t}\right)$ over the entire state space. An alternative is to use a reoptimization approach as in Tejada-Guibert et al. (1993). With this approach, the Bellman function is implemented forward with the SDP-derived benefit-to-go functions as inputs.

$$
\begin{aligned}
& F_{t}\left(\boldsymbol{S}_{t}, \boldsymbol{Q}_{t}\right) \\
& =\max _{D_{t}}\left[B_{t}\left(\boldsymbol{S}_{t}, \boldsymbol{Q}_{t}, D_{t}\right)+\sum_{q}\left\{p_{p, q}^{t} \cdot F_{t+1}^{*}\left(\boldsymbol{S}_{t+1}, \boldsymbol{Q}_{t+1}\right)\right\}\right]
\end{aligned}
$$

where $\boldsymbol{S}_{t}$ and $\boldsymbol{Q}_{t}$ are the simulated system state (storage) and inflows at stage $t$, and $p_{p, q}^{t}$ is the transition probability (Markov Chain) between inflow class $p$ at time stage $t$ and inflow class $q$ at time stage $t+1$. The $\boldsymbol{S}_{t+1}$ and $\boldsymbol{Q}_{t}$ values are not subjected to a discrete grid. The reoptimization provides time series of allocation decisions and the corresponding $\lambda$ values associated with the system's nodes, which correspond to the MROC.

\subsection{From MROC values to pricing policies}

The results given by the SDP algorithm are the optimal allocation policies, benefits and MROC values at each point of the discrete mesh. Those values vary with the time stage of the year, storages and inflows. A pricing scheme based on those values would be in theory the most efficient. Highly variable prices are normal in hydropower production, in which deregulated electricity markets' prices and demands vary even during the same day and, in consequence, hydropower producers need to make decisions on very short notice, independently of previous choices. However, this situation is distinctly different in consumptive demands, especially in irrigated agriculture. The majority of farmers make most of their decisions in an annual or inter-annual basis (area to be irrigated, cropping pattern and so on), where inyear choices are dependent on decisions in previous time stages. Farmers act as risk-averse decision-makers, since errors in the expectations of crop prices, input costs and water deliveries can cause significant economic losses. For those reasons, a pricing policy based on the raw MROC values would introduce too much uncertainty in the water price and thus in the agricultural sector. On the other hand, the pricing schemes derived from MROC values were conceived as the basis for a process involving discussion, negotiation and approval of a certain simple pricing policy with certain consensus among the stakeholders. As a result, the raw MROC values previously obtained have to be post-processed in order to transform them into simpler a priori scarcity-based pricing policies, so that the rule can be negotiated and known beforehand by everybody, allowing farmers to react accordingly with a more predictable price. Several operations must be carried out to transform the time series of MROC into a step pricing policy depending on the system state vari- 
ables $\left(\boldsymbol{t}, \boldsymbol{S}_{t}, \boldsymbol{Q}_{t}\right)$, in which a step function defines the price to be applied each time period. Those operations can be summarized as MROC values of aggregation/disaggregation, MROC statistical analysis, and step pricing policy construction. Although the SDP method was used to obtain the MROC time series, the operations explained below can be used regardless of the algorithm employed (another stochastic one such as SDDP, deterministic optimization or simulation) to provide MROC time series.

The aggregation/disaggregation of the MROC time series previously obtained is required in order to derive pricing functions at a certain spatial and temporal scale. Regarding the spatial dimension of the intended pricing policy, different pricing schedules for raw water in different zones in the system will better capture the MROC spatial variability. However, the complexity of pricing policies will probably imply greater implementation difficulties. With regard to the temporal scale, as stated earlier, pricing policies varying at a lower time resolution (seasonal or monthly) are more accurate than annual ones, although they might also face more implementation problems and higher uncertainty in future prices. Defining a general procedure to aggregate/disaggregate MROC time series is difficult, since it depends on the desired pricing policy features and each system's unique features. An example of the aggregation/disaggregation process for the specific features of the desired pricing policy is shown in the case study section.

Once the aggregated MROC values are obtained, their cumulative probability distribution can be determined. Several characteristic values can then be chosen using different percentiles of the cumulative probability distribution. Those characteristic values can be used to estimate the MROC-state relationship by (1) sorting the time series of state variables obtained with SDP according to their respective aggregated MROC values, (2) selecting the MROC-state pairs in which the MROC value was a characteristic one, and (3) organizing the results in the form of state-MROC steps. To sum up, the method presented in this paper can be divided in the following steps:

1. definition of the main pricing policy features;

2. development of a hydro-economic stochastic programming model of the system;

3. determination of MROC (marginal water values or $\lambda$ values) time series at the reference nodes (e.g., main reservoirs);

4. aggregation/disaggregation of MROC time series to calculate the aggregated MROC values;

5. development of a statistical analysis over the aggregated MROC values to obtain their cumulative probability distribution;

6. building of $k$ steps by (a) choose $k$ different cumulative probability values (characteristic values),

(b) sorting according to the aggregated MROC values the system state values obtained in the stochastic programming run,

(c) obtaining, for each characteristic value, the system states associated with it,

(d) summarizing all the possible state values associated with each characteristic value in the form of steps,

7. definition of several step pricing policies based on the obtained steps.

Pricing policies can be simulated to assess their performance and to compare them to the SDP results and to other alternatives such as different operating rules. In case the pricing policies' performance is found to be inadequate, the process must be restarted: the pricing policies' features are reassessed and the build-up and analysis stages must be redone. The most straightforward way to determine its adequacy is to quantify the forgone benefits that the users would be willing to accept as counterpart of using a simpler pricing policy. It is impossible to establish a unique threshold value since it totally depends on the system features. An alternative approach, employed in the case study of this paper, is to compare the performance of the pricing policy with the one achieved by the optimal operating rules expressed by the SDP results. In that way, a pricing policy could be considered as adequate as long as it obtains similar economic returns than to for the optimal policy.

\subsection{Case study: Mijares River basin (Spain)}

The Mijares River basin is located in eastern Spain (Fig. 2). It is characterized by the existence of several relevant water springs at its headwater (Mas Royo and Babor), the implementation of conjunctive-use water strategies to improve water management (Andreu and Sahuquillo, 1987), and the existence of an allocation framework accepted by all the users (SCRM, 1974). Regulated by the Arenós $\left(93 \mathrm{Mm}^{3}\right.$ ) and Sichar $\left(49 \mathrm{Mm}^{3}\right)$ reservoirs, surface water is mostly devoted to agricultural purposes (mainly orange trees), with groundwater as complementary or substitutive resource, while urban demands are entirely supplied using groundwater. There are 10.499 ha irrigated exclusively by surface water and 11.622 ha irrigated by surface and groundwater.

The Mijares River simplified flow network is shown in Fig. 3. Although the groundwater supply is significant in the lower basin (Plana de Castellón aquifer), it has not been explicitly represented in the optimization model, as there is no hydraulic connection between the river and the aquifer (disconnected aquifer). Upstream, stream-aquifer interaction is implicit in the inflow (discharge) time series. Seepage equations are also added in certain lower reaches of the river. Consequently, the demands supplied entirely by groundwater 


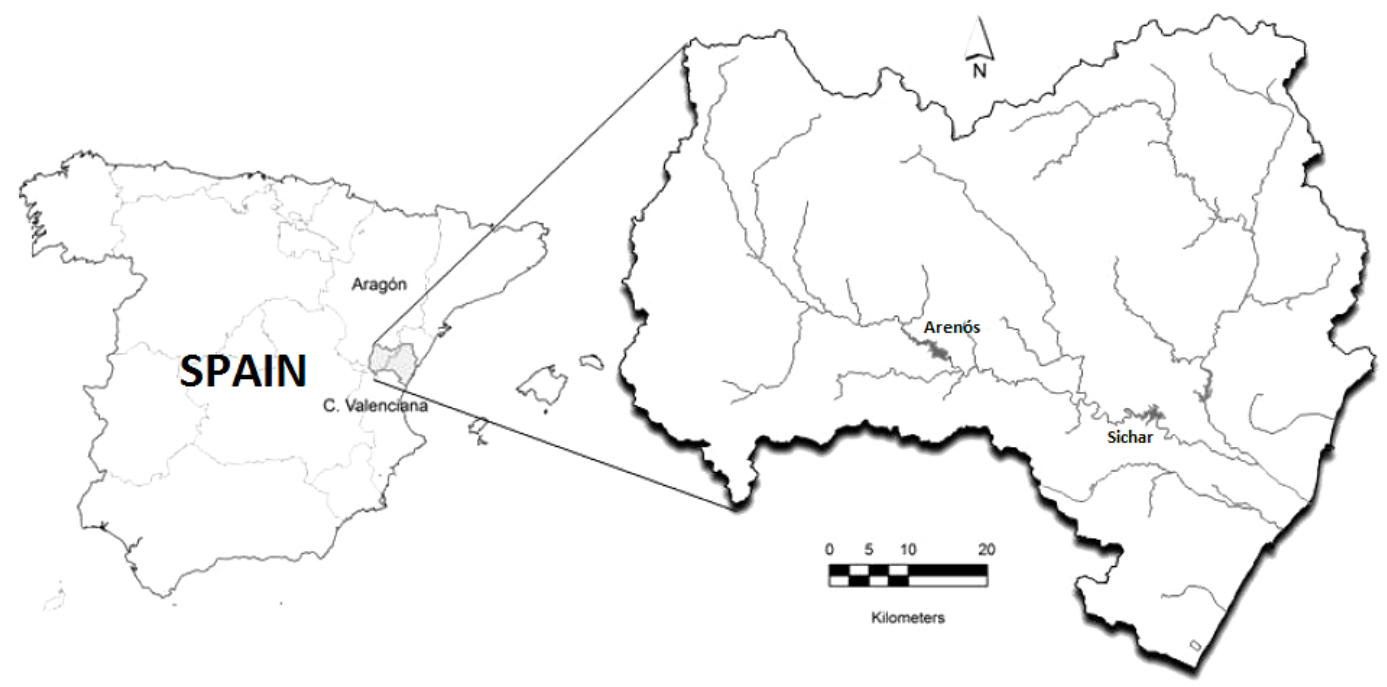

Figure 2. Mijares River basin location (eastern Spain).

Table 1. Characteristic values of elements of the Mijares River network.

\begin{tabular}{ll}
\hline Element & Characteristic value \\
\hline Arenós reservoir & $93 \mathrm{Mm}^{3}$ capacity \\
Sichar reservoir & $49 \mathrm{Mm}^{3}$ capacity \\
Upper basin inflow & $138 \mathrm{Mm}^{3}$ annual discharge \\
Middle basin inflow & $55 \mathrm{Mm}^{3}$ annual discharge \\
Traditional irrigation district & $83.5 \mathrm{Mm}^{3}$ annual demand \\
MC canal irrigation district & $7.6 \mathrm{Mm}^{3}$ annual demand \\
CC100 canal irrigation district & $16.3 \mathrm{Mm}^{3}$ annual demand \\
CC220 canal irrigation district & $11.9 \mathrm{Mm}^{3}$ annual demand \\
Minimum flow downstream Sichar & $0.2 \mathrm{Mm}^{3}$ annual requirement
\end{tabular}

have not been considered, and the mixed-supplied demands have been reduced by an amount equivalent to its groundwater supply. The characteristics of each element are shown in Table 1.

Current water management agreements give priority to the supply to the traditional irrigation district (ID), which has been using water since the 13 th century, over the remaining IDs (established in mid 20th century). In year 1970, before the construction of the Arenós dam (with public funding), an agreement was signed between users to regulate the use of the Sichar reservoir (funded by the traditional ID) (SCRM, 1974). That agreement established a monthly storage limit for the Sichar reservoir below which only the traditional ID can be supplied (see Fig. 4). That agreement continued to be applied after construction of the Arenós reservoir, but referred to the total system storage (Arenós and Sichar).

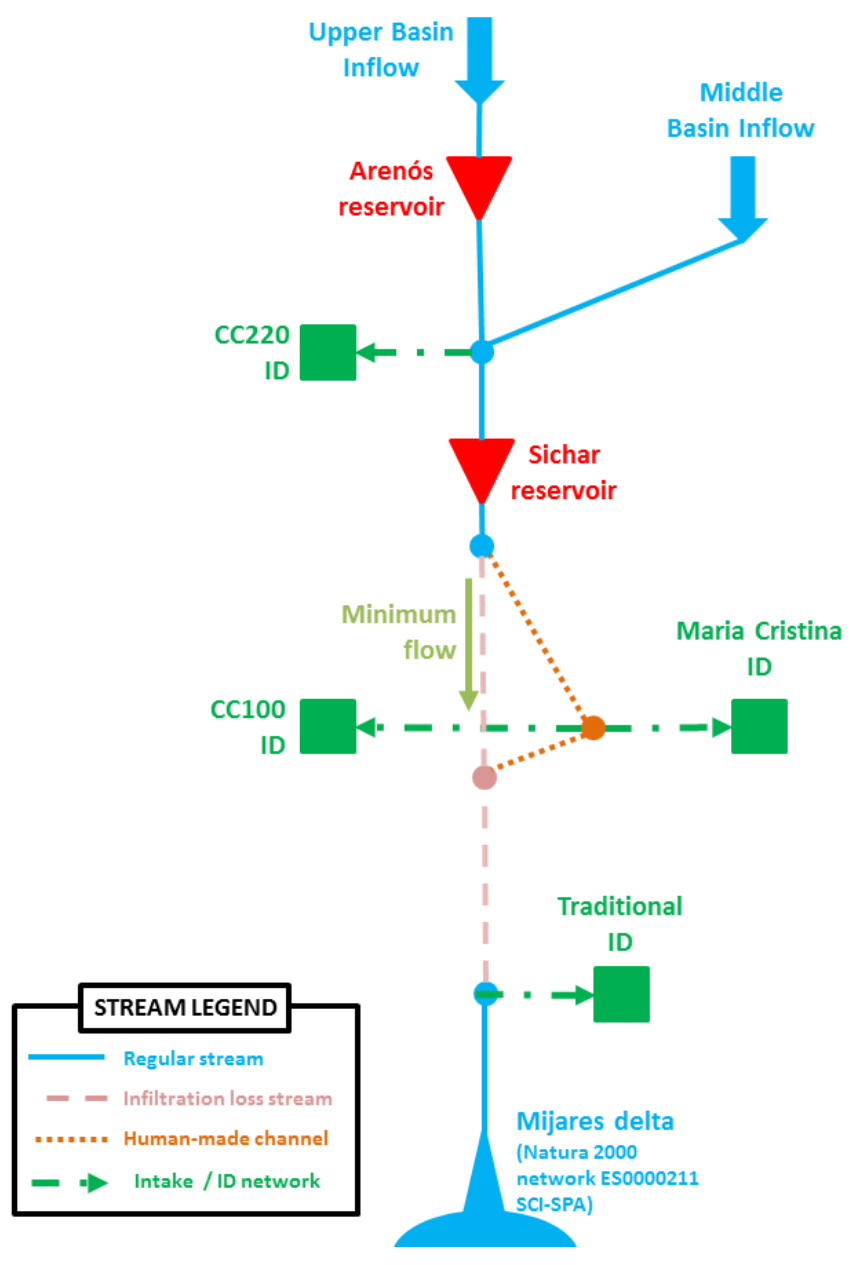

Figure 3. Mijares River network schematic. 


\subsection{SDP hydro-economic model of the Mijares River}

The SDP hydro-economic model comprises all the elements previously described and depicted in Fig. 4. A monthly time step was used. The hydrologic variables $\left(q_{t}, t=1, \ldots, 12\right)$ were discretized into four equally likely intervals per subbasin, each one represented by a characteristic value. Water demand curves are derived from Alvarez-Mendiola (2012). The minimum flow requirement has been considered as a constraint. A lag-1 Markov chain captures the temporal persistence found in the inflow data. The discrete storage classes adopted were 13 (Arenós) and 7 (Sichar). Minimum flows, demand curves, evaporation and infiltration losses, stream capacities and benefits (obtained as the sum of integrations under all the demand curves) are also taken into account in the model. The model was built using a generalized SDP algorithm developed using GAMS software (Macian-Sorribes and Pulido-Velazquez, 2014). This model was optimized, for an infinite horizon, taking target storages as decision variables.

\section{Results}

\subsection{SDP-obtained benefits, policies and MROC values}

The monthly policies and benefits obtained depend on a vector consisting of four variables: Arenós storage, Sichar storage, upper basin inflow and middle basin inflow. The optimal decisions obtained with the algorithm followed the classic "rule of thumb" of reservoirs in series devoted to water supply - fill the upper reservoirs first, and empty the lower reservoirs first (Lund and Guzman, 1999) - as the results empty first Sichar (the lower reservoir) and fill first Arenós (the upper reservoir). In addition, traditional ID users are subject to greater water deficits compared to the other ones, inverting the current criteria, caused by the river seepage in the lower Mijares streams.

A reoptimization procedure was applied to obtain the time series of MROC values at the Arenós and Sichar reservoirs, depicted compared with the sum of storages in Fig. 5. The plots show the same values during most of the historical time series. The slight differences between them found in certain time stages correspond to the opportunity cost of the CC220 ID delivery. Water values increase between 1977 and 1986, a period that corresponds to the largest drought suffered in the Mijares River basin. The average MROC value is equal to EUR $0.15 \mathrm{~m}^{-3}$, ranging from EUR 0 to $0.68 \mathrm{~m}^{-3}$.

\subsection{Pricing policies in the Mijares River basin}

Regarding the aggregation/disaggregation of the MROC time series at the Arenós and Sichar reservoirs, the pricing policy used was defined at basin-wide scale. This decision has been made considering the proximity of the intakes for the demands and the possibility of releasing water from the two reservoirs to satisfy almost all of them. The chosen temporal scale for the pricing policy was annual, with the same pricing policy for all the months. For simplicity, the state variable for defining the pricing schedule was the sum of the storage in the Arenós and Sichar reservoirs, without considering the corresponding monthly inflow. That departs from the SDP formulation but is consistent with the current management policies, based exclusively on storages. The aggregation operation driven by these features was simply a non-weighted average of the MROC values at the Arenós and Sichar reservoirs, as the MROC values are almost coincident for both reservoirs.

Figure 6 shows the MROC cumulative probability distribution. To establish pricing policies, we sampled the 5th $\left(\right.$ EUR $\left.0 \mathrm{~m}^{-3}\right)$, 25th (EUR $\left.0.06 \mathrm{~m}^{-3}\right), 50$ th $\left(\right.$ EUR $0.13 \mathrm{~m}^{-3}$ ), 75th (EUR $0.24 \mathrm{~m}^{-3}$ ) and 95th (EUR $0.51 \mathrm{~m}^{-3}$ ) percentiles. The MROC-storage pairs were then organized in intervals (as depicted in Fig. 7). Each interval or step represents the range of storage values associated with that MROC.

The previous steps were used to define the pricing policies. Firstly, the storage space was divided into intervals of $25 \mathrm{Mm}^{3}$. A price was then defined for each interval as either the minimum or the maximum or the average over the MROC values associated with the steps found within the interval. As a result, a set of 15 pricing policies was obtained. Figure 7 shows some of them, corresponding to policies regarding maximum between steps (pricing policy 1), average (pricing policy 2) and minimum (pricing policy 3 ). The remaining pricing policies were based on different combinations between prices obtained in the first three.

\subsection{Pricing policy performance by hydro-economic modeling}

Each pricing policy was simulated for the 1940-2009 period with a hydro-economic simulation model, previously built using MatLab (Macian-Sorribes, 2012), whose features are identical to the SDP one. This model implements the network shown in Fig. 3 with the corresponding element features (storage capacity, historical monthly inflows, seepage losses equations, etc.), the current demand priority scheme (first the traditional ID, then the rest), and the current system operation scheme (first fill Arenós, first empty Sichar and avoid as much as possible the streams subjected to seepage losses). More details can be found in Macian-Sorribes (2012). This simulation model calculates at each month the price that corresponds to the available storage, redefines water demands using the demand curves, and then allocates resources using the system's river network and infrastructure. Simulation results are then analyzed and compared to the performances obtained with both current and SDP-derived policies (Table 2). Figure 8a shows the time series of benefits resulting from SDP-derived policies (the optimal policies obtained from the SDP once interpolated as suggested 


\section{Mijares Management Rule Curve}

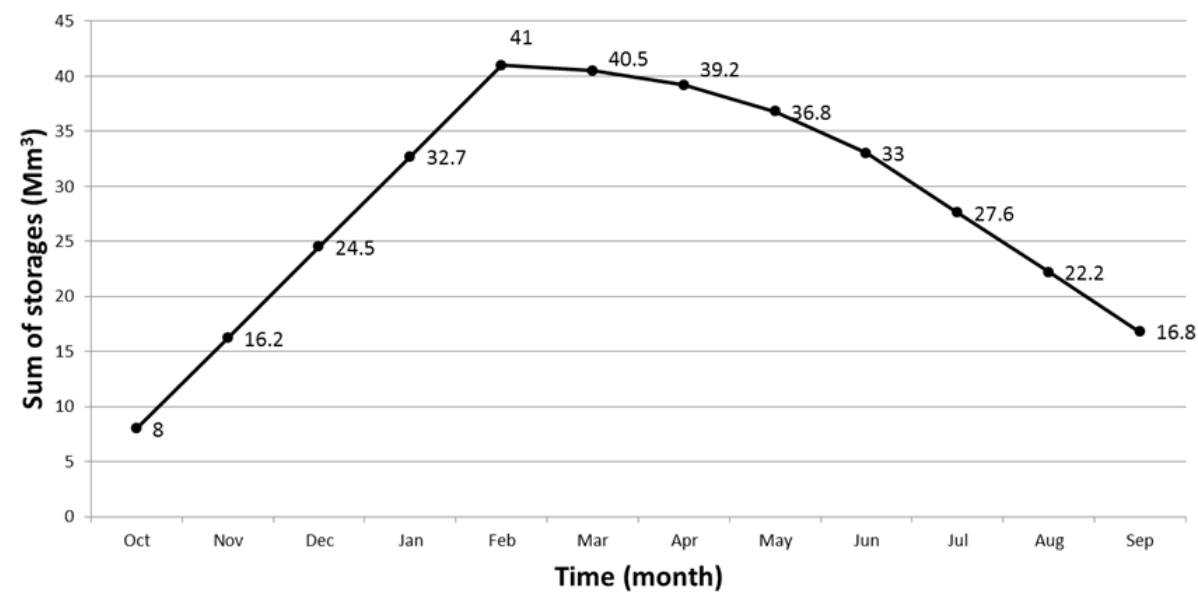

Figure 4. Current management rule curve established in the Mijares River basin.

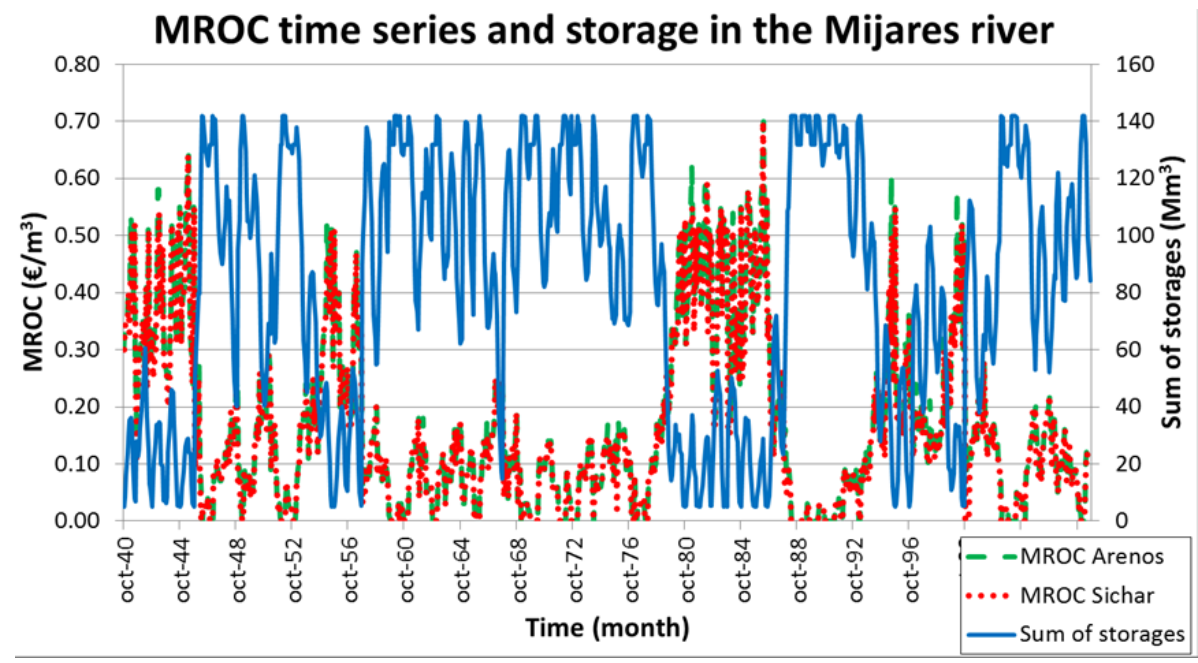

Figure 5. MROC time series and storages in the Mijares River.

by Tejada-Guibet in 1993), current management rules and the best pricing policies for the 1940-2009 period.

Regarding Table 2 and Fig. 8a, only slight differences can be found between policies. All pricing policies increase the economic results of current management policies by around EUR 0.70 million per year, being similar to the ones obtained with the direct use of the SDP policies. For that reason, we consider those pricing policies to be adequate, as it was not necessary to test complex ones. This situation is caused by the natural robustness of the Mijares River water system and by the homogeneity of the cropping pattern (mainly citrus crops, mostly oranges) found in the basin. The improvement caused by pricing policies is due to temporal reallocations: the prices hedge the immediate supplies to allow for greater deliveries in the next months. In that way, the deficits and their induced scarcity costs are distributed over several months of slight delivery reductions rather than a single large deficit. As the income losses are non-linear with respect to the deliveries, that deficit distribution improves the total economic return for the system. Despite having the same global benefits, the way they are distributed among the users' changes for all the pricing policies tested; thus it is necessary to take them into account when deciding which one to be implemented.

Focusing on the most severe historical drought faced by the Mijares Basin, from year 1977 to 1986 (Table 2, Fig. 8b), the differences on benefits between the current management and the SDP results are higher (around EUR 1.10 million per year), indicating that SDP-derived policies hedge available resources better against the drought events. To sum up, the pricing policy application resulted in greater benefits. Especially in drought situations, the adoption of these strategies 


\section{Combined MROC cumulative probability distribution}

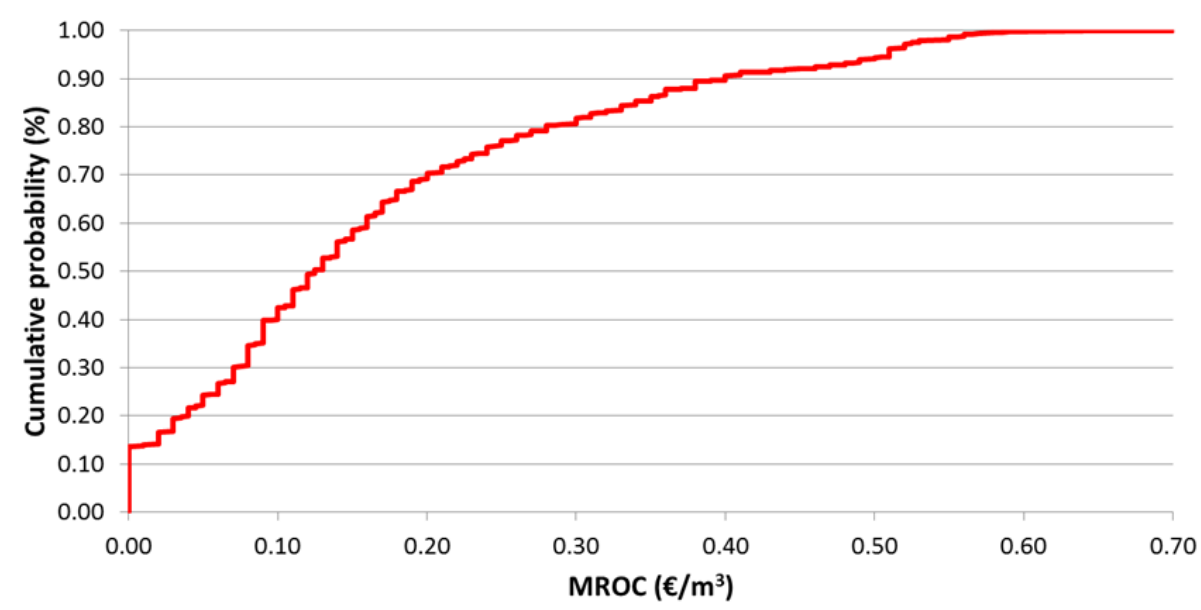

Figure 6. Combined MROC cumulative probability distribution.

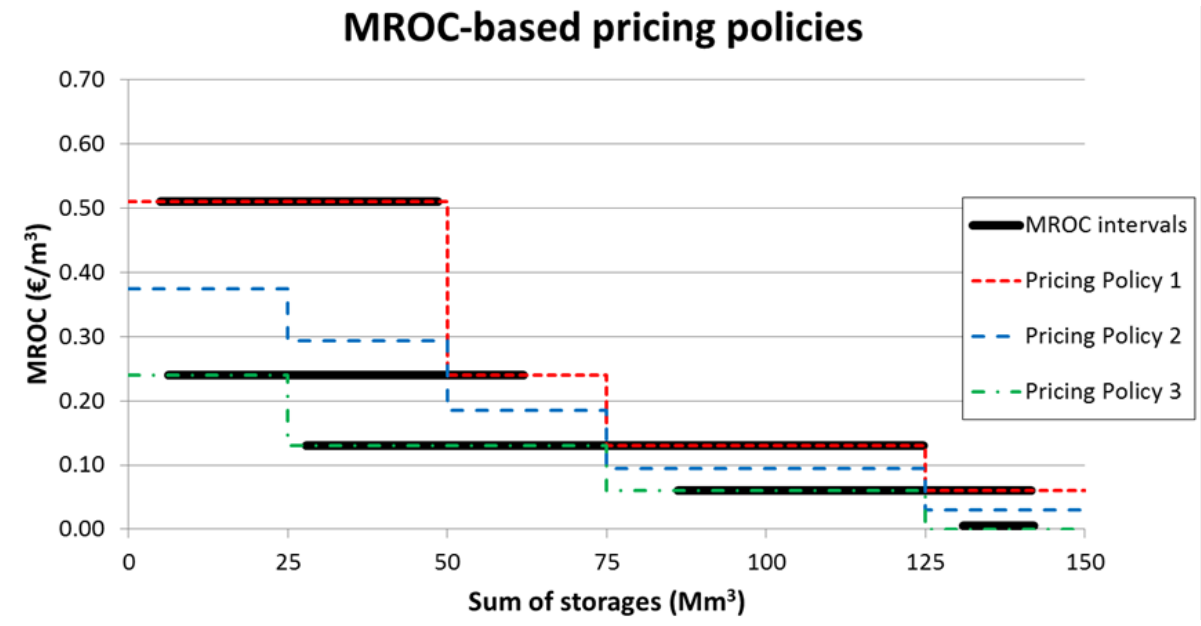

Figure 7. MROC-based pricing policies.

Table 2. Benefits for the 1940-2009 and 1977-1986 periods with stochastic optimization (SDP), current management rules and pricing policies.

\begin{tabular}{lcclll}
\hline Simulation & $\begin{array}{l}\text { Traditional } \\
\text { M EUR }\end{array}$ & $\begin{array}{l}\text { MC } \\
\text { M EUR }\end{array}$ & $\begin{array}{l}\text { CC100 } \\
\text { M EUR }\end{array}$ & $\begin{array}{l}\text { CC220 } \\
\text { M EUR }\end{array}$ & $\begin{array}{l}\text { Total } \\
\text { M EUR }\end{array}$ \\
\hline & 1940-2009 benefits per demand and total \\
\hline SDP & 44.49 & 4.14 & 8.56 & 6.56 & 63.75 \\
Current policies & 46.31 & 3.60 & 7.42 & 5.73 & 63.06 \\
Pricing policy 10 & 44.99 & 4.06 & 8.29 & 6.47 & 63.81 \\
Pricing policy 11 & 45.00 & 4.05 & 8.29 & 6.46 & 63.81 \\
Pricing policy 12 & 45.05 & 4.04 & 8.27 & 6.44 & 63.81 \\
\hline \multicolumn{7}{c}{$1977-1986$ benefits per demand and total } & \\
\hline SDP & 35.97 & 3.22 & 6.80 & 5.07 & 51.05 \\
Current policies & 42.05 & 1.69 & 3.52 & 2.68 & 49.93 \\
Pricing policy 4 & 37.11 & 3.06 & 6.09 & 4.86 & 51.12 \\
Pricing policy 5 & 37.11 & 3.06 & 6.09 & 4.86 & 51.12 \\
\hline
\end{tabular}

would lead to a greater economic performance and to a more efficient water use.

\section{Discussion and conclusions}

This paper presents a method to design an efficient scarcitybased pricing policy based on marginal water values (MROC) derived from stochastic programming. The method is applied to a case study, the Mijares River basin, in Spain. The results show that the benefits from the application of the resulting pricing policies are close to those obtained by the optimal SDP policy for both the entire historical hydrological data series and the drought conditions. By pricing marginal water opportunity costs, water would be reallocated to the highest-valued uses, significantly increasing the total net benefit of water use in the basin (by EUR 0.75 million per year). 

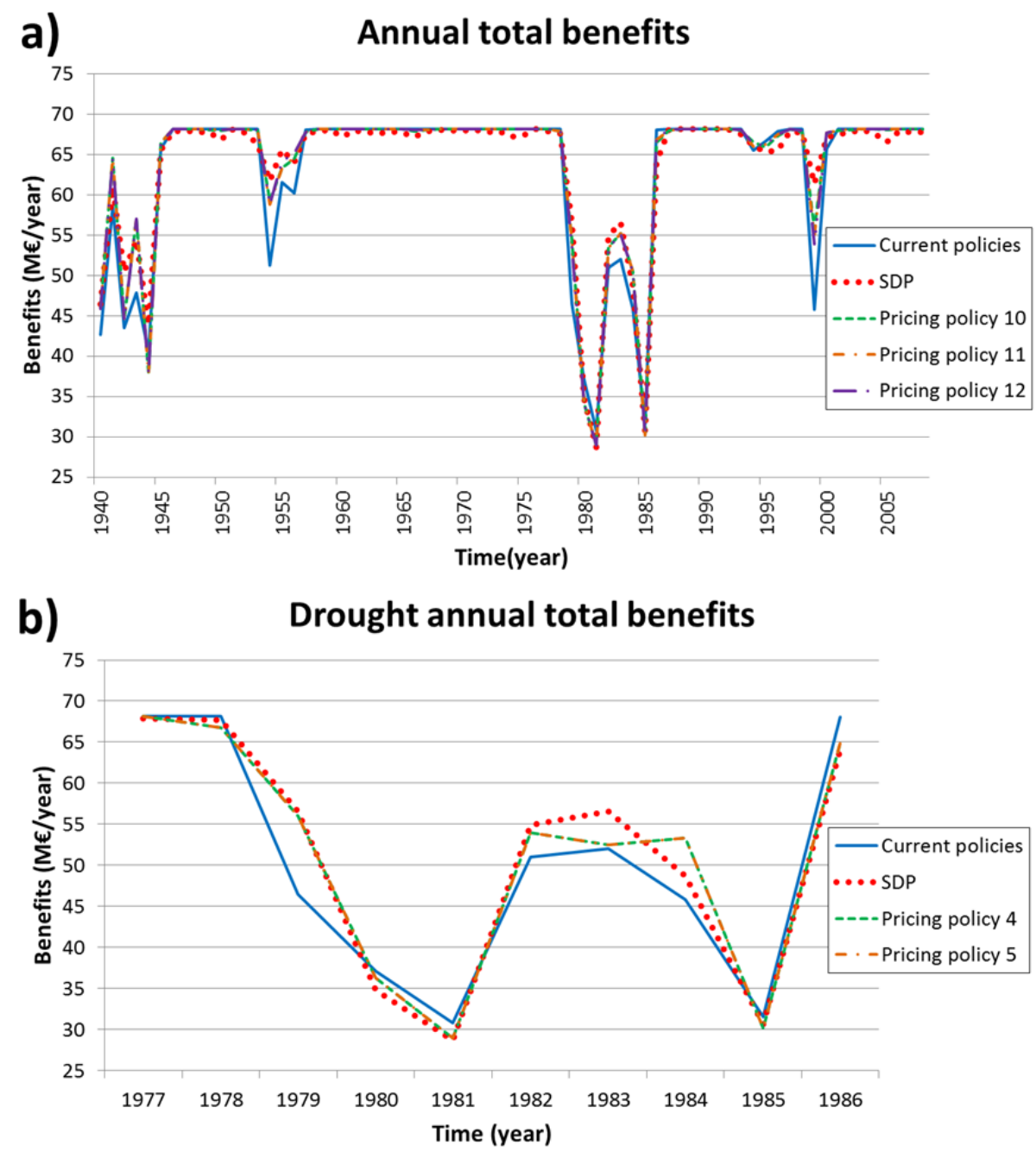

Figure 8. Annual total benefits comparison for the 1940-2009 period (a) and for the 1977-1986 drought (b).

The reason why a simple pricing policy is able to achieve a similar performance as that of a complex optimal operating rule in this case study is due to the in-year time pattern possessed by this policy: the majority of the MROC values that determined the water prices for the lower storage levels correspond to start-of-refill ones, while the MROC values associated with high storage levels are start-of-drawdown ones. For that, the prices triggered vary across time in accordance to the refill-drawdown cycle of the system, reproducing in some way the water value annual cycle.

Given the uncertainties associated with the inputs of the model, the predictions concerning the pricing policy performance are therefore uncertain. The most important source of uncertainty are the demand curves, since they directly affect the MROC values and the reliability of the simulated performance of a pricing policy. Given the strong influence of the demand curves in the results, demand curves should be properly estimated and tested. The robustness in the estimation of the demand curves will be subject to the availability of the proper information for the economic characterization of the water uses in the basin as well as the suitability of the method used in the definition of those curves. This could be a limitation in the applicability of the method to certain cases. The resulting pricing policies should be in any case regarded just as a starting point for a negotiation process involving the users and policymakers to determine the final prices to be charged for water abstraction. On the other hand, the pricing policies defined in this paper are conceived exclusively as economic instruments for achieving an economically efficient use of water. Financial issues (such as revenue sufficiency and cost recovery) and other goals of pricing policies like equity and environmental sustainability should be considered as well.

Unlike the method proposed in Pulido-Velazquez et al. (2013), this one uses a stochastic programming approach instead of deterministic programming or simulation. It also employs a different method to derive the pricing policies based on the MROC and state time series. 
The MROC values measure the opportunity cost associated with water use. Therefore, in order to determine the final prices charged to the users, the cost recovery component of the supply costs (operation, maintenance and capital charges) and the environmental externalities should be added (Rogers et al., 2002). The main objective in the design of the pricing policies discussed here focuses on the use of water prices as economic instrument for an efficient management of the interaction between supply and demand. The role of pricing for the cost recovery of water services (pricing as financial instruments) will require a complementary analysis.

Comparing pricing policies with water markets, both will be theoretically valid approaches for enhancing economic efficiency in water allocation in the system. Nowadays in Spain water markets are allowed by law but, in practice, only in a few occasions have they been operative and never in this system (Palomo-Hierro et al., 2015). Factors like high transaction costs, farmers' reluctance to participate, low physical connectivity, etc., often prevent more transfers. While the experience and literature on water markets is more abundant, water pricing is clearly underused regarding its potential for dealing with water scarcity. Despite its limitations, drawbacks, barriers and issues for its implementation, water pricing offers some interesting features: contributes to match supply and demand, generates revenues, and maintains customer choices (against command and control policies). On the other hand, the river basin authority holds the formal control of the system, which is essential for addressing environmental requirements, third party effects and so on.

Regarding the established methodology and the case study, several conclusions can be drawn.

1. Stochastic programming is a useful tool for estimating optimal policies and MROC time series under hydrological uncertainty. These time series capture and summarize the overall performance of the optimization policies and can be therefore used to assess pricing policies able to be applied at the basin scale.

2. Pricing policies defined using MROC data series, after statistical analysis and step building, are adequate to enhance a system's global economic efficiency. They establish a univocal relationship between the system state (storages and inflows) and a water price based on the marginal value of water in a reservoir, linking the price concept to the MROC one.

3. Participatory framework processes might be desirable to define the features and characteristics that the pricing policies should have, in order to find as much consensus as possible for its implementation.

4. The proposed methodology aims at designing efficient pricing policies. Other issues should be incorporated in the design of a final pricing policy, such as cost recovery of financial costs related to water services and of environmental cost (externalities), as well as equity issues and other social objectives (eg. rural development and environmental protection).

5. Pricing policy is one of the economic policy instruments that can be implemented to adapt individual decisions to collective goals. We can also apply a mix of them (water markets, pollution taxes, etc.) in order to better reach the social and environmental targets in the management of water resource systems.

Acknowledgements. This study has been partially funded by the European Union's Seventh Framework Program (FP7) ENHANCE (number 308.438). In addition, the authors acknowledge the editor and reviewers for their helpful and constructive comments.

Edited by: F. Pappenberger

\section{References}

Alvarez-Mendiola, E.: Diseño de una política eficiente de precios del agua integrando costes de oportunidad del recurso a escala de cuenca, $\mathrm{PhD}$ dissertation, Universitat Politècnica de València, Valencia, Spain, 2012 (in Spanish).

Andreu, J., and Sahuquillo, A.: Efficient aquifer simulation in complex systems, J. Water Res. Pl.-ASCE, 113, 110-129, 1987.

CHJ: Esquema provisional de Temas Importantes, Ministerio de Medio Ambiente y Medio Rural y Marino, Confederación Hidrográfica del Júcar, Valencia, Spain, 2009 (in Spanish).

Dandy, G. C., McBean, E. A., and Hutchinson, B. G.: A model for constrained optimum water pricing and capacity expansion, Water Resour. Res., 20, 511-520, 1984.

Dinar, A., Rosegrant, M. W., and Meinzen-Dick, R.: Water Allocation Mechanisms - Principles and Examples, Agriculture and Natural Resources Department, World Bank, Washington, DC, USA, 2007.

European Commission: Directive 2000/60/Ec of the European Parliament and of the Council, of 23 October 2000, establishing a framework for community Action in the Field of Water Policy, Official Journal of the European Communities (OJL), 327, 1-73, 2000.

Fisher, F., Huber-Lee, A., and Amir, I.: Liquid Assets: An Economic Approach for Water Management and Conflict Resolution in the Middle East and Beyond, RFF Press, Washington, DC, USA, 2005.

Garrick, D., Siebentritt, M. A., Aylward, B., Bauer, C. J., and Purkey, A.: Water markets and freshwater ecosystem services: policy reform and implementation in the Columbia and MurrayDarling Basins, Ecol. Econ., 69, 366-379, 2009.

Griffin, R. C.: Effective water pricing, J. Am. Water Resour. As., 37, 1335-1347, 2001.

Griffin, R. C.: Water Resource Economics: The Analysis of Scarcity, Policies, and Projects, The MIT Press, Cambridge, USA, 402 pp., 2006.

Gysi, M. and Loucks, D. P.: Some long run effects of water-pricing policies, Water Resour. Res., 7, 1371-1382, 1971. 
Harou, J. J., Pulido-Velazquez, M., Rosenberg, D. E., MedellínAzuara, J., Lund, J. R., and Howitt, R. E.: Hydro-economic models: concepts, design, applications, and future prospects, J. Hydrol., 375, 627-643, 2009.

Heinz, I., Pulido-Velazquez, M., Lund, J., and Andreu, J.: Hydroeconomic modeling in river basin management: implications and applications for the European Water Framework Directive, Water Resour. Manag., 21, 1103-1125, 2007.

Howe, C. W., Schurmeier, D. R., and Shaw Jr., W. D.: Innovative approaches to water allocation: the potential for water markets, Water Resour. Res., 22, 439-445, 1986.

Johansson, R. C., Tsur, Y., Roe, T. L., Doukkali, R., and Dinar, A.: Pricing irrigation water: a review of theory and practice, Water Policy, 4, 173-199, 2002.

Karamouz, M., Houck, M. H., and Delleur, J. W.: Optimization and simulation of multiple reservoir systems, J. Water Res. Pl.ASCE, 118, 71-81, 1992.

Kelman, K., Stedinger, J. R., Cooper, L. A., Hsu, E., and Yuan, S.Q.: Sampling stochastic dynamic programming applied to reservoir operation, Water Resour. Res., 26, 447-454, 1990.

Labadie, J. W.: Optimal operation of multireservoir systems: stateof-the-art review, J. Water Res. Pl.-ASCE, 130, 93-111, 2004.

Lund, J. R. and Guzman, J.: Derived operating rules for reservoirs in series or in parallel, J. Water Res. Pl.-ASCE, 125, 143-153, 1999.

Macian-Sorribes, H.: Utilización de Lógica Difusa en la Gestión de Embalses, Master Thesis dissertation, Universitat Politècnica de València, Valencia, Spain, 2012 (in Spanish).

Macian-Sorribes, H. and Pulido-Velazquez, M.: Hydro-economic optimization under inflow uncertainty using the SDP-GAMS generalized tool, in: Evoling Water Resources Systems: Understanding, Predicting and Managing Water-Society Interactions, IAHS Press, Wallingford, UK, 410-415, 2014.

Massarutto, A.: El precio de agua: herramienta básica para una política sostenible del agua?, Ingeniería del Agua, 10, 293-326, 2003 (in Spanish).

Meinzen-Dick, R. and Mendoza, M.: Alternative water allocation mechanisms indian and international experiences, Econ. Polit. Weekly, 31, A25-A30, 1996.

Mousavi, J. J., Ponnambalam, K., and Karray, F.: Reservoir operation using a dynamic programming fuzzy rule-based approach, Water Resour. Manag., 19, 655-672, 2005.

Nandalal, K. D. W. and Bogardi, J. J.: Dynamic Programming Based Operation of Reservoirs: Applicability and Limits, Cambridge University Press, Cambridge, UK, 144 pp., 2007.

Palomo-Hierro, S., Gomez-Limon, J. A., and Riesgo, L.: Water Markets in Spain: Performance and Challenges, Water 2015, 7, 652-678, 2015.

Pulido-Velazquez, M., Jenkins, M., and Lund, J. R.: Economic values for conjunctive use and water banking in southern California, Water Resour. Res., 40, W03401, doi:10.1029/2003WR002626, 2004.

Pulido-Velazquez, M., Andreu, J., Sahuquillo, A., and PulidoVelazquez, D.: Hydro-economic river basin modelling: the application of a holistic surface-groundwater model to assess opportunity costs of water use in Spain, Ecol. Econ., 66, 51-65, 2008.
Pulido-Velazquez, M., Alvarez-Mendiola, E., and Andreu, J.: Design of efficient water pricing policies integrating basinwide resource opportunity costs, J. Water Res. Pl.-ASCE, 139, 583-592, 2013.

Riegels, N., Pulido-Velazquez, M., Doulgeris, C., Sturm, V., Jensen, R., Moller, F., and Bauer-Gottwein, P.: Systems analysis approach to the design of efficient water pricing policies under the EU Water Framework Directive, J. Water Res. Pl.-ASCE, 139, 574-582, 2013.

Rogers, P., de Silva, R., and Bhatia, R.: Water is an economic good: How to use prices to promote equity, efficiency and sustainability, Water Policy, 4, 1-17, 2002.

SCRM: Convenio de Bases para la Ordenación de las Aguas del río Mijares, Ministerio de Obras Públicas, Transportes y Medio Ambiente, Confederación Hidrográfica del Júcar, Valencia, Spain, 50 pp., 1974 (in Spanish).

Stedinger, J. R., Sule, B. F., and Loucks, D. P.: Stochastic dynamic programming models for reservoir operation optimization, Water Resour. Res., 20, 1499-1505, 1984.

Tejada-Guibert, J. A., Johnson, S. A., Stedinger, J. R.: Comparison of two approaches for implementing multireservoir operating policies derived using stochastic dynamic programming, Water Resour. Res., 29, 3969-3980, 1993.

Tilmant, A. and Kelman, R.: A stochastic approach to analyze trade-offs and risks associated with large-scale water resources systems, Water Resour. Res., 43, W06425, doi:10.1029/2006WR005094, 2007.

Tilmant, A., Pinte, D., and Goor, Q.: Assessing marginal water values in multipurpose multireservoir systems via stochastic programming, Water Resour. Res., 44, W12431, doi:10.1029/2008WR007024, 2008.

Tilmant, A., Goor, Q., and Pinte, D.: Agricultural-to-hydropower water transfers: sharing water and benefits in hydropowerirrigation systems, Hydrol. Earth Syst. Sci., 13, 1091-1101, doi:10.5194/hess-13-1091-2009, 2009.

Tilmant, A., Arjoon, D., and Fernandes Marques, G.: Economic value of storage in multireservoir systems, J. Water Res. Pl.ASCE, 140, 375-383, 2014.

US Army Corps of Engineers (USACE) Hydrologic Engineering Center (HEC): Developing Seasonal and Long-Term Reservoir System Operation Plans Using HEC-PRM, US Army Corps of Engineers, Hydrologic Engineering Center, Davis, California, USA, 1996.

Ward, F. and Pulido-Velazquez, M.: Efficiency, equity and sustainability in a water quantity-quality optimization model in the Rio Grande basin, Ecol. Econ., 66, 23-37, 2008.

Wurbs, R. A.: Reservoir-system simulation and optimization models, J. Water Res. Pl.-ASCE, 119, 455-472, 1993.

Young, R. A.: Water economics, in: Water Resources Handbook, McGraw-Hill, New York, NY, USA, 3.1-3.57, 1996.

Young, R. A.: Determining the Economic Value of Water: Concepts and Methods, RFF Press, Washington, DC, USA, 375 pp., 2005. 